\title{
Immunotherapy for penile cancer
}

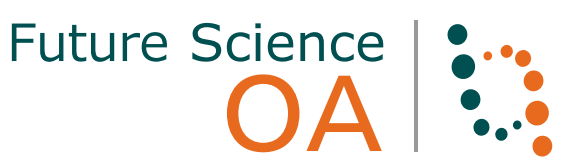

\author{
"We speculate that a potential setting of experimental \\ use of VGX 3100 in a clinical trial may include men with \\ p16INK4a-positive penile cancer who have undergone \\ complete surgical resection, but are at significant risk of \\ disease recurrence."
}

First draft submitted: 10 March 2017; Accepted for publication: 10 March 2017; Published online: 2 May 2017

Keywords: environment $\bullet \mathrm{HPV} \bullet$ immunotherapy $\bullet$ nivolumab $\bullet$ penile cancer

\section{Background}

Penile carcinoma is a rare disease, with incidence rates varying in the range of $1-10$ cases per 100,000 men depending on ethnicity, geographic area, cultural background and social habits [1,2]. Tumorigenesis of penile carcinoma is governed by a complex interplay of multiple causative factors. These include initiating agents, such as tobacco toxins, UV radiation and, possibly, household contaminants from solid fuel combustion, which have been implicated in carcinoma of the cervix [3], as well as promoting agents, such as cytokines related to chronic inflammation and high-risk HPV, mainly HPV-16 and HPV-18 [2], which are well known for their major etiopathogenetic role in cervix carcinomas [4]. In patients with carcinoma of the penis, keratinizing squamous cell and verrucous lesions harbor high-risk HPV only in $30 \%$ of cases and coexist with squamous cell hyperplasia and/or lichen sclerosus, while basaloid and warty carcinomas, which are composed of small, undifferentiated basaloid cells with koilocytic changes, harbor HPV in $80-100 \%$ of cases [2]. Positivity to highrisk HPV has both prognostic and biological implications in penile cancer. In fact, HPV infection may be associated with better outcomes in penile cancer men, as reported in a retrospective study of 171 patients showing a 5-year cancer-specific survival rate of 78 and $93 \%$, respectively, in the high-risk HPVnegative subgroup versus the high-risk HPVpositive subgroup (log rank test $\mathrm{p}=0.03$ ) [5].
Furthermore, while HPV-positive tumors express more frequently HER3 and cytoplasmic Akt1, HPV-negative tumors express more frequently phosphorylated EGFR [6], which is consistent with the negative prognostic effect associated with presence of phosphorylated EGFR [7].

\section{The role of HPV as a potential target for immunotherapy}

The HPV proteins E6 and E7 play a key role in HPV-mediated carcinogenesis. In addition to inactivating p53, E6 can bind to transcription factors (myc), autocrine motility factors that regulate cell adhesion and polarity (paxillin), apoptosis-inducing factors $(\mathrm{Bcl} 2)$ and replication and DNA repair factors $(\mathrm{mcm} 7)$, while the E7 protein inactivates the retinoblastoma tumor-suppressor protein via proteasome-dependent degradation and causes p16INK4a overexpression, which can be detected on immunohistochemistry and can be employed as a reliable diagnostic marker of high-risk HPV infection [8]. Interestingly, the p16INK4a protein is overexpressed both in intraepithelial and invasive lesions $[9,10]$, and can serve as a reliable diagnostic histologic biomarker of HPV infection in penile cancers. On the basis of the established etiopathogenetic role of HPV in a subgroup of penile cancer patients, we wish to speculate here that HPV-associated antigens have the potential to provide specific targets for an immunotherapy approach in men with penile cancer. At the present time, two vaccines

\author{
Carlo Buonerba*,1,2, Martina \\ Pagliuca', Francesca Maria \\ Vitrone', Ilaria Ascione ${ }^{1}$, Ivana \\ Elefante ${ }^{2}$, Vittorio Riccio', \\ Francesca Romano², Sabino \\ De Placido' \& Giuseppe \\ Di Lorenzo ${ }^{1}$ \\ 'Dipartimento di Medicina Clinica e \\ Chirurgia, Università Federico II di Napoli, \\ Naples, Italy \\ 2Istituto Zooprofilattico Sperimentale del \\ Mezzogiorno, Portici, Italy \\ *Author for correspondence: \\ carbuone@hotmail.com
}

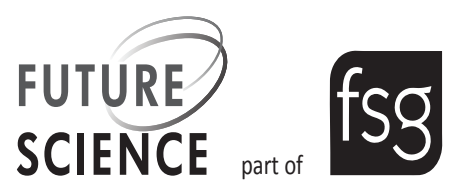


based on HPV L1 virus-like particles are commercially available and approved in young women in order to prevent HPV infection, that is Gardasil ${ }^{\circledR}$ (Merck \& Co., NJ, USA) and Cervarix ${ }^{\circledR}$ (GlaxoSmithKline, England, UK). While Gardasil contains virus-like particles from HPV-16 and HPV-18, but also from low-risk carcinogenic genotypes 6 and 11, which cause benign genital warts, Cervarix contains virus-like particles from HPV-16 and HPV-18 only [11]. Spontaneous clearance of high-risk HPV occurs in approximately a third of women after 6 months and in approximately half of the women after 12 months [11]. Although available preventive anti-HPV vaccines are able to induce both antibody and cellular responses, they are not able to improve spontaneous HPV clearance rate [11], so they cannot be considered as candidates for an immunotherapy approach in HPV-mediated tumors. In fact, while HPV L1 protein is predominantly expressed in terminally differentiated keratinocytes, expression of the E6 and E7 proteins is retained through all of the epithelial layers and through multiple stages of infection. As a result, an immune response against E6 and E7 antigens may be effective to clear E6- and E7-expressing neoplastic cells [12].

\section{Future perspective: VGX-3100 \& anti-PD1/ PD-L1 agents}

The novel immunotherapy agent VGX-3100 (Inovio Pharmaceuticals, PA, USA), which is delivered via electroporation, is based on two property DNA synthetic plasmids that encode the E6 and E7 genes of HPV-16 and HPV-18 [12]. Electroporation uses brief electric pulses to cause transient and reversible permeabilization of the cell membrane, which optimizes transfection of nucleic acids, with a 100-1000-fold enhancement of plasmid delivery and gene expression [12]. VGX-3100 was tested in a pivotal Phase I study in 18 women with recurrent cervical intraepithelial neoplasia (CIN) grade 2 or 3, showing encouraging results in terms of $\mathrm{HPV}$-specific $\mathrm{CD} 8^{(+)}$and $\mathrm{CD}^{+}$ T-cell response [12]. In a subsequent double-blind, placebo-controlled Phase IIb study [13], 167 patients with CIN2/3 associated with HPV-16 and HPV-18 were randomly assigned in a $3: 1$ ratio to receive $6 \mathrm{mg}$ VGX-3100 $(\mathrm{n}=125)$ or $1 \mathrm{ml}$ placebo solution $(\mathrm{n}=$ 42), both given intramuscularly at 0,4 and 12 weeks. The primary objective of the study, that was improvement of histopathological regression rate of CIN 2/3 lesions, was met in the modified intention-to-treat analysis, with 55 (48.2\%) of the 114 patients receiving VGX-3100 and $12(30.0 \%)$ of the 40 placebo recipients showing regression to CIN 1 or no disease. The safety profile of VGX-3100 was excellent, with the majority of patients showing injection-site reactions, and erythema being significantly more frequent in the VGX-3100 group $(98 / 125,78.4 \%)$ with respect to the placebo group $(24 / 42,57 \cdot 1 \%$; $p=0.007)$. While VGX-3100 may be useful to avoid morbidity of surgical treatment in women with CIN2/3 cancers, this agent may provide survival benefits in patients with limited therapeutic options such as those with penile carcinoma. As we reported previously, prognosis of penile cancer is excellent in patients with noninvasive disease, while in patients with invasive tumors 5 -year cancerspecific survival rates vary in the ranges of $75-93 \%$, $40-70 \%, 33-50 \%$ and $20-34 \%$ in men with $\mathrm{cN} 0$, cN1, cN2 and cN3 disease [14]. Prognosis of patients requiring systemic chemotherapy for advanced disease is poor - approximately 6-12 months [15,16]. We speculate that a potential setting of experimental use of VGX 3100 in a clinical trial may include men with p16INK4a-positive penile cancer who have undergone complete surgical resection, but are at significant risk of disease recurrence. Conversely, we speculate that in men with metastatic penile cancer that tested positive for HPV 16/18, given the high burden of the disease, combination of an active, antigen-specific immunotherapy treatment such as VGX 3100 with an anti-PD (Programmed Death)-1/PD-L1 (Programmed DeathLigand 1) agent may be beneficial. In fact, in a recently published retrospective study, 23 (62.2\%) of 37 primary tumors were positive for PD-L1 expression, with a strong positive correlation of PD-L1 expression in primary and metastatic samples [17]. Of note, anti PD-1 agent nivolumab has shown efficacy in head and neck cancers, which share histologic (squamous histology) and pathogenic (HPV infection) characteristics with penile cancer [18].

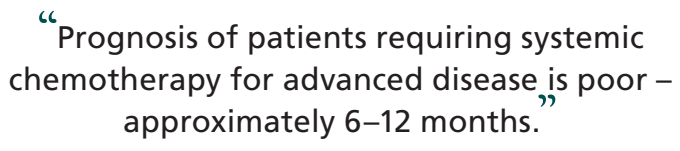
approximately 6-12 months."

In conclusion, although the industry may show little interest in rare diseases such as penile cancer, a continued effort should be made by independent investigators to contribute to advances in the treatment of such a devastating disease, given its high morbidity and mortality.

\section{Author contributions}

All authors contributed to the conception and writing of the paper, and to its critical revision.

\section{Financial \& competing interests disclosure}

The authors have no relevant affiliations or financial involvement with any organization or entity with a financial interest in or financial conflict with the subject matter or materials discussed in the manuscript. This includes employment, 
consultancies, honoraria, stock ownership or options, expert testimony, grants or patents received or pending, or royalties.

No writing assistance was utilized in the production of this manuscript.

\section{References}

1 Sonparde G, Pagliaro LC, Buonerba C, Dorff TB, Lee RJ, Di Lorenzo G. Penile cancer: current therapy and future directions. Ann. Oncol. 24(5), 1179-1189 (2013).

2 Rubin MA, Kleter B, Zhou M et al. Detection and typing of human papillomavirus DNA in penile carcinoma: evidence for multiple independent pathways of penile carcinogenesis. Am. J. Pathol. 159(4), 1211-1218 (2001).

3 Josyula S, Lin J, Xue X et al. Household air pollution and cancers other than lung: a meta-analysis. Environ. Health 14, 24 (2015)

4 Forman D, De Martel C, Lacey CJ et al. Global burden of human papillomavirus and related diseases. Vaccine 30(Suppl. 5), F12-F23 (2012).

5 Lont AP, Kroon BK, Horenblas S et al. Presence of highrisk human papillomavirus DNA in penile carcinoma predicts favorable outcome in survival. Int. J. Cancer 119(5), 1078-1081 (2006).

6 Stankiewicz E, Prowse DM, Ng M et al. Alternative HER/ PTEN/Akt pathway activation in HPV positive and negative penile carcinomas. PLoS ONE 6(3), e17517 (2011).

7 Di Lorenzo G, Perdona S, Buonerba C et al. Cytosolic phosphorylated EGFR is predictive of recurrence in early stage penile cancer patients: a retropective study. J. Transl. Med. 11, 161 (2013).

8 Lehoux M, D’abramo CM, Archambault J. Molecular mechanisms of human papillomavirus-induced carcinogenesis. Public Health Genomics 12 (5-6), 268-280 (2009).

9 Mannweiler S, Sygulla S, Winter E, Regauer S. Two major pathways of penile carcinogenesis: HPV-induced penile cancers overexpress p16ink4a, HPV-negative cancers associated with dermatoses express p53, but lack p16ink4a overexpression. J. Am. Acad. Dermatol. 69(1), 73-81 (2013).

10 Chaux A, Pfannl R, Lloveras B et al. Distinctive association of p16INK4a overexpression with penile intraepithelial

\section{Open access}

This work is licensed under the Creative Commons Attribution 4.0 License. To view a copy of this license, visit http://creativecommons.org/licenses/by/4.0/

neoplasia depicting warty and/or basaloid features: a study of 141 cases evaluating a new nomenclature. Am. J. Surg. Pathol. 34(3), 385-392 (2010).

11 Hildesheim A, Herrero R, Wacholder S et al. Effect of human papillomavirus 16/18 L1 viruslike particle vaccine among young women with preexisting infection: a randomized trial. JAMA 298(7), 743-753 (2007).

12 Bagarazzi ML, Yan J, Morrow MP et al. Immunotherapy against HPV16/18 generates potent $\mathrm{TH} 1$ and cytotoxic cellular immune responses. Sci. Transl. Med. 4(155), 155 ra138 (2012).

13 Trimble CL, Morrow MP, Kraynyak KA et al. Safety, efficacy, and immunogenicity of VGX-3100, a therapeutic synthetic DNA vaccine targeting human papillomavirus 16 and 18 E6 and E7 proteins for cervical intraepithelial neoplasia 2/3: a randomised, double-blind, placebocontrolled Phase IIb trial. Lancet 386(10008), 2078-2088 (2015).

14 Buonerba C, Di Lorenzo G, Calderoni G et al. The evolving landscape in advanced penile cancer. Future Sci OA 1(3), FSO9 (2015).

15 Buonerba C, Di Lorenzo G, Pond G et al. Prognostic and predictive factors in patients with advanced penile cancer receiving salvage (2nd or later line) systemic treatment: a retrospective, multi-center study. Front. Pharmacol. 7, 487 (2016).

16 Di Lorenzo G, Buonerba C, Federico P et al. Cisplatin and 5 -fluorouracil in inoperable, stage IV squamous cell carcinoma of the penis. BJU Int. 110 (11 Pt B), E661-E666 (2012).

17 Udager AM, Liu TY, Skala SL et al. Frequent PD-L1 expression in primary and metastatic penile squamous cell carcinoma: potential opportunities for immunotherapeutic approaches. Ann. Oncol. 27(9), 1706-1712 (2016).

18 Ferris RL, Blumenschein G Jr, Fayette J et al. Nivolumab for recurrent squamous-cell carcinoma of the head and neck. N. Engl. J. Med. 375(19), 1856-1867 (2016). 